EPJ Web of Conferences 45, 01049 (2013)

DOI: $10.1051 /$ epjconf/20134501049

(C) Owned by the authors, published by EDP Sciences, 2013

\title{
The impact of the orifice plate deformation on the differential pressure value
}

\author{
R. Kiš ${ }^{1}$, M. Janovcová ${ }^{1}$, M. Malcho ${ }^{1}$, J. Jandačka $^{1}$ \\ ${ }^{1}$ Department of power engineering, University of Žilina, 01001 Žilina, Slovakia
}

\begin{abstract}
This work aims to determine the impact of orifice plate deformation on the differential pressure at the high-pressure natural gas pipelines. The article focuses on the differences of the pressure values, velocity values and flow directions between deformed and undeformed orifice plate. The article contains deformation analysis of the orifice plate and CFD simulations of flowing natural gas through the orifice plates. CFD simulations contain basic models of the turbulence for both types of orifice plate. Whole research is based on the elimination of the negative influence of the deformation on the precise flow measuring of natural gas at the high-pressure pipelines.
\end{abstract}

\section{Introduction}

Measurements with high accuracy play nowadays very important role. The increasing tendency of measuring accuracy is supported worldwide by the sale of large amounts of oil and natural gas, in which every small mistake in measurements is calculated by millions of cubic meters of fuel. This mistake means great financial loss for both, for seller or for buyer.

In Slovakia and other European Union countries are mostly used pressure differential devices, turbine flowmeters and ultrasonic flowmeters for accurate measurement and verification flow in the high-pressure natural gas conduits (table 1).

Table 1. The accuracies of the most used flowmeters.

\begin{tabular}{|c|c|c|c|}
\hline Type & $\begin{array}{c}\text { Typical } \\
\text { accuracy }\end{array}$ & $\begin{array}{c}\text { Max. } \\
\text { pressure } \\
(\mathbf{M P a})\end{array}$ & $\begin{array}{c}\text { Max. } \\
\text { temperature } \\
\left({ }^{\circ} \mathbf{C}\right)\end{array}$ \\
\hline $\begin{array}{c}\text { Pressure } \\
\text { differential } \\
\text { devices }\end{array}$ & $\begin{array}{c}0.6 \div 2 \% \\
\text { from } \\
\text { range }\end{array}$ & 50 & 1000 \\
\hline $\begin{array}{c}\text { Turbine } \\
\text { flowmeters }\end{array}$ & $\begin{array}{c}0.1 \div 2 \% \\
\text { from } \\
\text { measured } \\
\text { value }\end{array}$ & 200 & 450 \\
\hline $\begin{array}{c}\text { Ultrasonic } \\
\text { flowmeters }\end{array}$ & $\begin{array}{c}1 \% \div 3 \% \\
\text { from } \\
\text { range }\end{array}$ & 20 & 200 \\
\hline
\end{tabular}

The most used are pressure differential devices. According to ISO 5167 (Measurement of fluid flow by means of pressure differential devices inserted in circular cross-section conduits running full) are standard pressure differential devices divided into orifice plates, nozzles, Venturi nozzles and Venturi tubes. The most common are orifice plates, which deals with part ISO 5167-1:2003 (Orifice plates). They are used mainly because of their high accuracy in measurements and relatively small production and operation costs. The fundament of the orifice plate operation consists of introducing a located restriction in the point where the measurement should be obtained. Such restriction changes the speed of the flow and causes a differential of pressures that is proportional to the fluid flow.

The objective of this work is to determine the applicability of the international standard ISO $5167-$ 2:2003 in high-pressure conduits.

\section{Methodology}

The principle of the method of measurement is based on the installation of an orifice plate into a pipeline in which a fluid is running full. The presence of the orifice plate causes a static pressure difference between the upstream and downstream sides of the plate. The equation of the mass flow $q_{m}$ for subcritical draining, used for the determination of the produced mass of natural gas (ISO 5167-2:2003) is shown below (1).

$$
q_{m}=\frac{C}{\sqrt{1-\beta^{4}}} \varepsilon \frac{\pi}{4} d^{2} \sqrt{2 \Delta p \rho_{1}}
$$

Parameters of this equation are detailed in table 2. 
Table 2. The accuracies of the most used flowmeters.

\begin{tabular}{|c|c|}
\hline Symbols & Parameters \\
\hline $\mathrm{C}$ & Discharge coefficient \\
\hline$\beta$ & Diameter ratio: $\beta=\mathrm{d} / \mathrm{D}$ \\
\hline$\varepsilon$ & Factor of expansion \\
\hline $\mathrm{d}$ & Diameter of the orifice \\
\hline$\Delta \mathrm{p}$ & Differential pressure \\
\hline$\rho_{1}$ & Density of fluid \\
\hline
\end{tabular}

Discharge coefficient $C$ is given by the Reader Harris/Gallagher equation:

$$
\begin{gathered}
C=0.5961+0.0261 \beta^{2}+0.000521\left(\frac{10^{6} \beta}{\operatorname{Re}_{\mathrm{D}}}\right)^{0,7}+ \\
+(0.0188+0.0063 \mathrm{~A}) \beta^{3,5}\left(\frac{10^{6}}{\operatorname{Re}_{\mathrm{D}}}\right)^{0,3}+(0.043+ \\
\left.+0.080 e^{-10 L_{1}}-0.123 e^{-7 L_{1}}\right) . \\
.\left(1-0.031\left(\mathrm{M}_{2}^{\prime}-0.8 \mathrm{M}_{2}^{\prime}{ }^{1,1}\right) \beta^{1,3}\right.
\end{gathered}
$$

Table 3. Parameters used in the equation of the discharge coefficient.

\begin{tabular}{|c|c|}
\hline Symbols & Parameters \\
\hline $\operatorname{Re}_{\mathrm{D}}$ & $\begin{array}{c}\text { Reynolds number calculated with } \\
\text { respect to D. }\end{array}$ \\
\hline $\mathrm{L}_{1}\left(=\mathrm{l}_{1} / \mathrm{D}\right)$ & $\begin{array}{c}\text { Quotient of the distance of the } \\
\text { upstream tapping from upstream } \\
\text { face of the plate and the pipe } \\
\text { diameter. }\end{array}$ \\
\hline $\mathrm{L}_{2}^{\prime}\left(=\mathrm{l}^{\prime}{ }_{2} / \mathrm{D}\right)$ & $\begin{array}{c}\text { Quotient of the distance of the } \\
\text { downstream tapping from } \\
\text { downstream face of the plate and } \\
\text { the pipe diameter. }\end{array}$ \\
\hline$M^{\prime}{ }_{2}=\frac{L_{2}^{\prime}}{1-\beta}$ & \begin{tabular}{l}
\hline$A^{\prime}-\left(\frac{1900 \beta}{\operatorname{Re}_{D}}\right)^{0,8}$ \\
\hline
\end{tabular} \\
\hline
\end{tabular}

For flange tapings arrangement is valid:

$$
L_{1}=L_{2}^{\prime}=\frac{25,4}{D}
$$

Factor of expansion is given by empirical formula:

$\varepsilon=1-\left(0,351+0,256 \beta^{4}+0,93 \beta^{8}\right)\left[1-\left(\frac{p_{2}}{p_{1}}\right)^{1 / \kappa}\right](4)$

Equation (4) is applicable only if:

$$
p_{2} / p_{1} \geq 0,75
$$

\section{Deformation of the orifice plate}

European standard ISO 5167-2:2003 defines maximum allowable $1 \%$ deflection from the plane unloaded by the action of differential pressure or any other tension.

Measuring tracks for measuring natural gas flow in high-pressure conduits are ordinary these dimensions $D=$ $730 \mathrm{~mm}, d=413 \mathrm{~mm}$, Material of orifice plate is stainless steel class 17 and thickness is $10 \mathrm{~mm}$. Input pressure is $5 \mathrm{MPa}$ and differential pressure at the orifice plate is $50 \mathrm{kPa}$. Daily volumetric flow is about 11 millions $\mathrm{Nm}^{3}$ / day.

The model was created in Inventor for the closer illustration of stress and deformation of orifice plate according to the data shown above (figure 1). Outer diameter of orifice plate was $D^{\prime}=762 \mathrm{~mm}$ and the diameter of the part, which is inside pipe, where natural gas streams $D=730 \mathrm{~mm}$. The ring between these two diameters with thickness $h=16 \mathrm{~mm}$ was defined as a fixed bond (In the figure is marked with grey color), which simply shows the mounting orifice plate with flange.

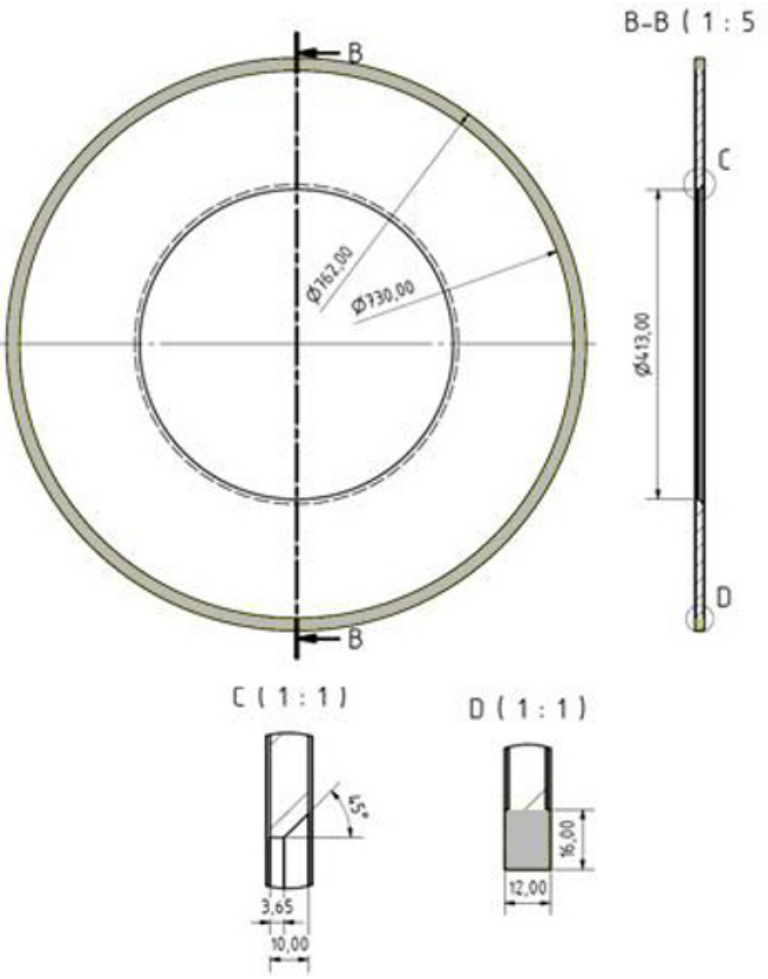

Fig. 1. Drawings of the orifice plate.

The biggest shift was appeared around the aperture of orifice plate (figure 2). This shift was 1.588 millimeters long. Maximum 1\% allowable deflection wasn't exceeded, but due to orifice plate and pipeline dimensions should be considered that the deformation probably change the angles of the leading edge of orifice plate and thereby influence the direction of flow of natural gas behind the orifice plate, which ultimately can 
affect the accuracy of the differential pressure at the orifice plate.

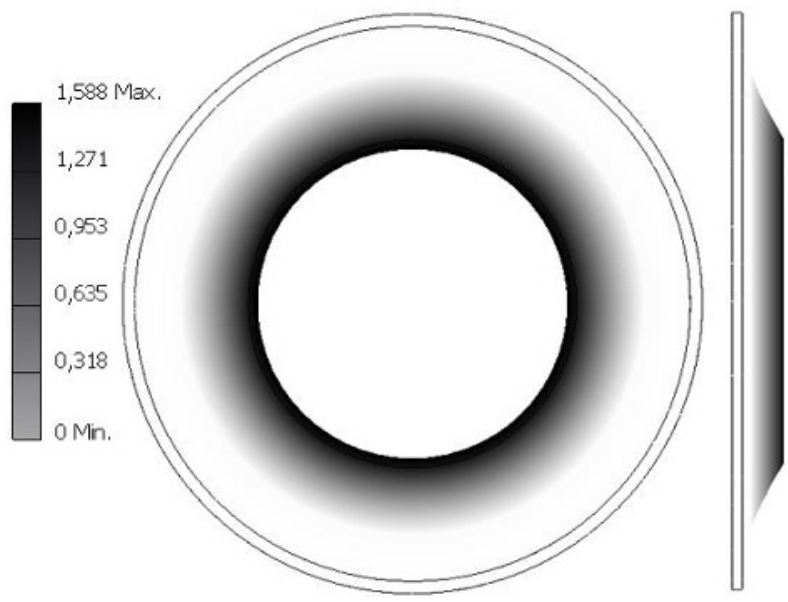

Fig. 2. Deformation of the orifice plate with shift [mm].

\section{Simulations}

CFD simulation was made after the deformation analysis. Two different models were created. First one consisted of two pipelines and undeformed orifice plate positioned between them. Second one had same two pipelines and deformed orifice plate according to the mentioned deformation analysis. As the most ideal model for compressible fluid (natural gas) was chosen $\mathrm{k}-\varepsilon$ model. Mass flow $(91 \mathrm{~kg} / \mathrm{s})$ was chosen as a boundary condition. Operating pressure was $101 \mathrm{kPa}$ and total pressure in the inlet to the model was $1.75 \mathrm{MPa}$. Shape deformation (shift) causes changes in the dispositions of the pressure fields behind the orifice plate. These changes are shown in the figure 3 .

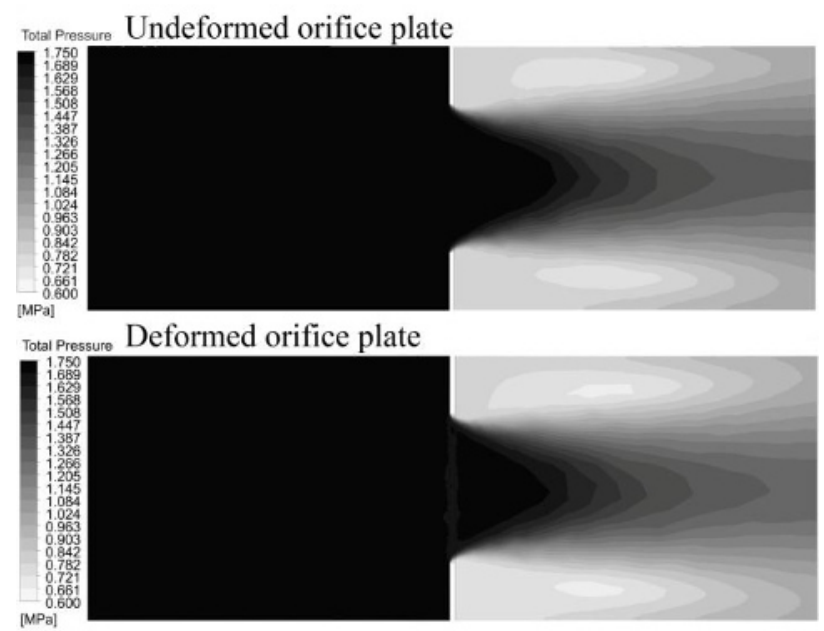

Fig. 3. Pressure fields in undeformed and deformed model.

Deformation caused a small reduction of the highpressure diameter value. Pressures in the distance of 4 millimeters behind the orifice plate raised by $0.7 \mathrm{kPa}$ (from $1665.5 \mathrm{kPa}$ to $1666.2 \mathrm{kPa}$ ) in the middle point of the pipeline and by $8.9 \mathrm{kPa}$ (from $802.7 \mathrm{kPa}$ to 811.6 $\mathrm{kPa}$ ) around the wall of the pipe (figure 4).

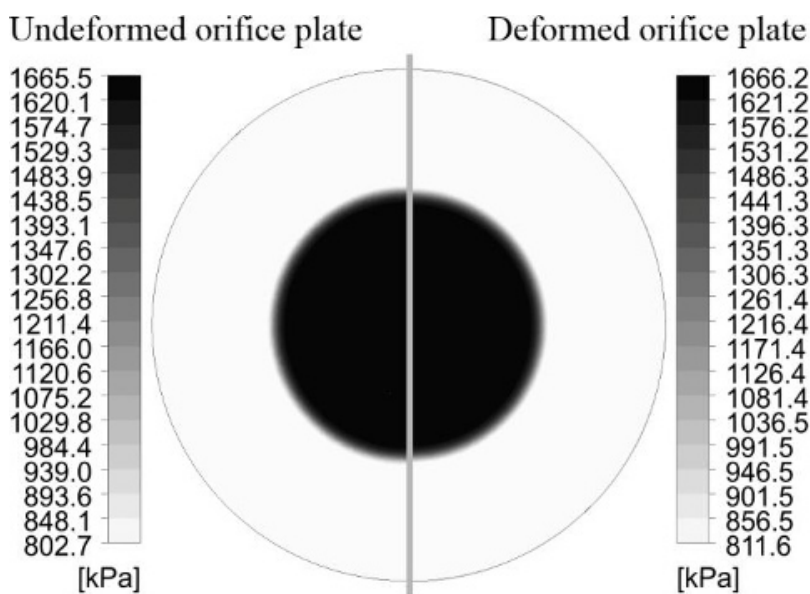

Fig. 4. Pressure fields in the plane placed 4 millimetres behind the orifice plate.

Pressures in the distance of 21 millimeters behind the orifice plate dropped by $0.3 \mathrm{kPa}$ (from $1668.7 \mathrm{kPa}$ to $1668.4 \mathrm{kPa}$ ) in the middle point of the pipeline and by $8.5 \mathrm{kPa}$ (from $804.1 \mathrm{kPa}$ to $812.6 \mathrm{kPa}$ ) around the wall of the pipe (figure 5).

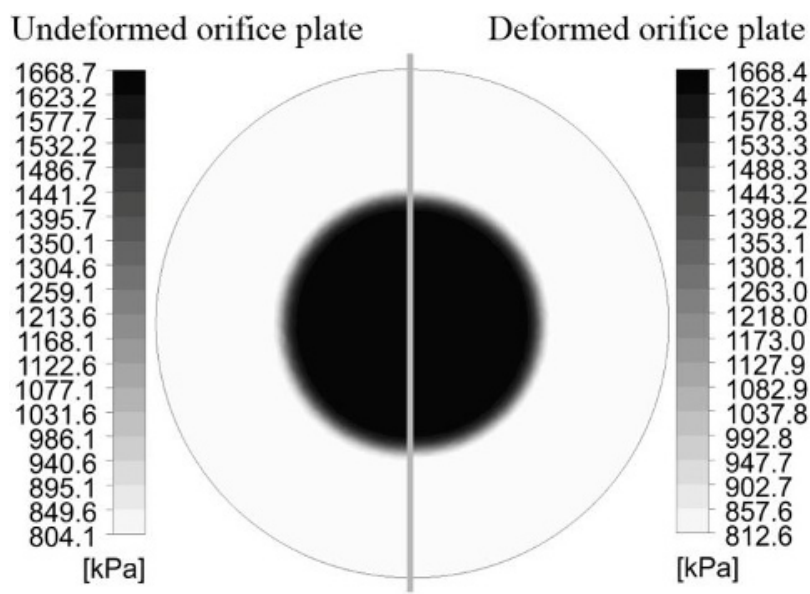

Fig. 5. Pressure fields in the plane placed 21 millimetres behind the orifice plate.

The distances 4 and 21 millimeters are boundaries, which were determined by the condition for flange tapings arrangement, where for parameter $a$ (distance) is valid:

$$
0.005 D \leq a \leq 0.03 D
$$

Pressure values were changed differently due to the change of the dispositions of the pressure fields.

If the pressure behind the orifice plate was changed then differential pressure, measured in front of and behind the orifice plate, was changed too.

Other parameters, which are influenced by the deformation are flow direction and velocity. In the deformed case is reverse flow behind the orifice plate stronger then in undeformed one (figure 6). This influence probably causes different pressure values between undeformed and deformed orifice plate. 
Undeformed orifice plate

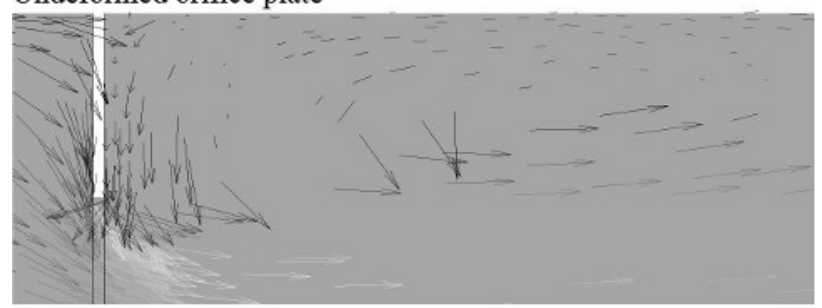

Deformed orifice plate

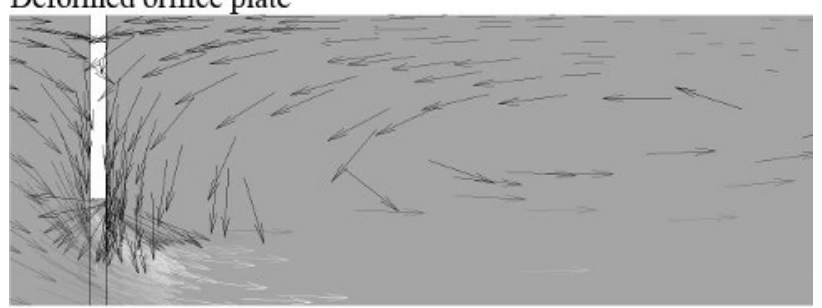

Fig. 6. Reverse flow behind the orifice plate.

Velocity profile was mainly changed around the output edge of the orifice plate. This difference can be seen in the figure 7 .

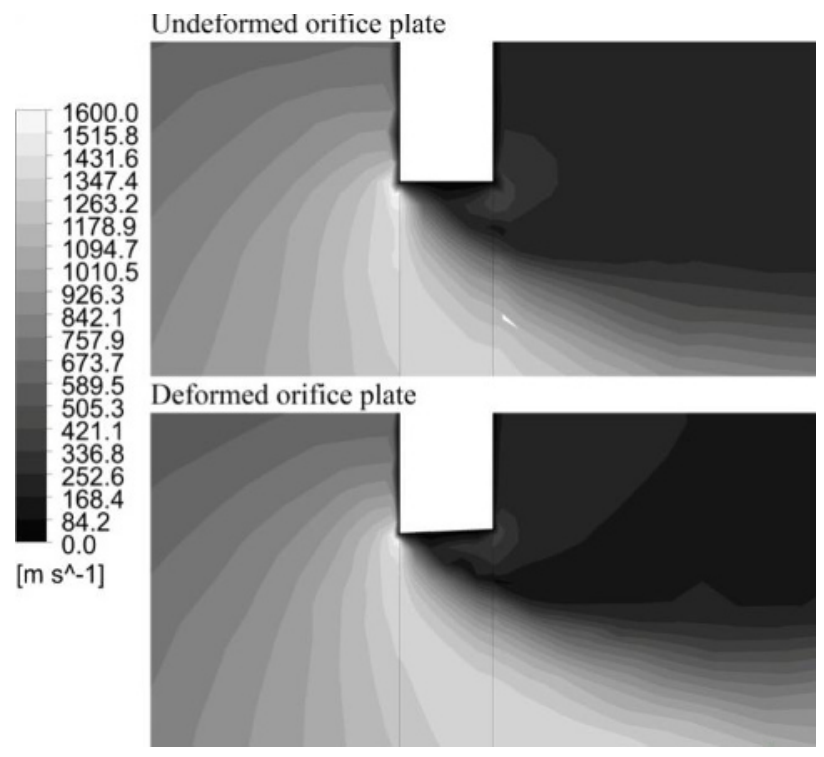

Fig. 7. Velocity profile around the aperture of the orifice plate.

\section{Conclusion}

This article shows, that differential pressure causes shape deformation on the orifice plate. This deformation influences flow direction, velocity of flowing natural gas, pressures behind the orifice plate and differential pressure measured in front of and behind the orifice plate positioned in the pipeline.

Next research will be focused on exact cases used in practice, like measuring of mass flow in the high-pressure transit pipelines. The impact of the deformation on accuracy of measurement will be examined.

\section{References}

1. J. Jandačka, M. Malcho, Slovgas: odborný plynárenský časopis. -ISSN 1335-3853. Roč. 15, n. 5 Slovakia (2006), p. 6-8.
2. M. Malcho, J. Jandačka, Š. Papučík, Acta Metallurgica Slovaca y. 13., n. 3 Slovakia (2007), p. 233-238.

3. R. Kiš, M. Janovcová, M. Malcho. The application of experimental and numerical methods in fluid mechanics and energy, Slovakia (2012). p. 136-140.

4. ISO 5167-1:2003, Measurement of fluid flow by means of pressure differential devices inserted in circular cross-section conduits running full - Part 1: General principles and requirements. International organization of Standardization, Slovakia.

5. ISO 5167-2:2003, Measurement of fluid flow by means of pressure differential devices inserted in circular cross-section conduits running full - Part 2: Orifice plates. International organization of Standardization, Slovakia.

6. A. Mederos, J. Lima, An international Journal, Brazilian archives of biology and technology, Brazil (2006).

7. R. Lenhard, S. Gavlas, 5th Annual International Travelling Conference for Young Researchers and PhD students. 2011, y. 5.

8. S. Gavlas, R. Lenhard, M. Malcho, Experimental fluid mechanics 2011: proceedings of the international conference. Liberec (2011). p. 801-808.

9. R. Lenhard. Power control and optimization: proceeding of fourth global conference (2010), Kuching, Malaysia. p. 4. 